\title{
The flexibility of steel hollow tubular sections subjected to thermal and mechanical loads
}

\author{
E. M. M. Fonseca ${ }^{1}$, F. Q. Melo ${ }^{2}$ \& R. A. F. Valente ${ }^{2}$ \\ ${ }^{1}$ Polytechnic Institute of Bragança, Portugal \\ ${ }^{2}$ University of Aveiro, Portugal
}

\begin{abstract}
Numerical analysis of hollow tubular sections is used as a starting tool to establish the reliability assessment of these elements when mechanically or thermally loaded. To quantify the material deformation behaviour of these elements resulting from ground motion, crack propagation, effects from high temperatures, theoretical and experiments analyses can be used for testing a service reliable guarantee. Structural hollow sections have excellent static properties, not only with regard to buckling and torsion, but also in the overall design of members. They can offer economic advantages compared to open sections. It is possible to change the strength by varying the wall thickness or filling the section with other material without changing the external geometry. Flexibility is an important parameter in hollow tubular systems when subjected to thermal or mechanical loads. This work presents a numerical analysis technique based on the finite element method for thermal and mechanical non-linear behaviour. Temperature field will be calculated according to non-steady conditions when submitted to standard ISO834 and non-linear material properties foreseen in Eurocode standards (EC1 and EC3). This work will present a complete study of the flexibility analysis for a wide range of pipe dimensions, and the obtained results are then compared with design rules.

Keywords: temperature, equivalent stress, tubular section, flexibility.
\end{abstract}

\section{Introduction}

There are several failure modes, which could affect piping systems. Failure by general yielding is due to an excessive plastic deformation, particularly when elevated temperatures prevail. Failure by fracture, on the other hand, occurs in 
brittle materials or due to cyclic loading, where after an initially small crack is developed, grow and propagation after each cycle occurs, resulting in sudden failure. Different theories of failure have been proposed to establish the point at which failure will occur under any type of combined loading. The expansion loads are usually due to thermal expansion, seismic anchor movements and building settlement. According with ASME B31.3 code, flexibility analysis is a requirement of most plant piping installations [1,2]. Code implementation requires the working knowledge of thermal expansion, material properties that are temperature dependent, formulas for stress intensification factors and flexibility factors which apply to all pipe components and accessories. Inherent flexibility is necessary to deal with the effects of thermal expansion and contraction. In preliminary piping layouts, the experienced designer must take into consideration such effects as the pipe size and wall thickness, and the maximum range of temperatures for the piping being subject to. Expansion joints may also be included for additional flexibility in tight areas. Anchor points and support locations can also be selected in order to constrain the pipe in all degrees of freedom, in the most general case being three translations and three rotations.

\section{Flexibility analysis}

Methods are available for determining the requirements for flexibility in a piping system: the computed stress range at any point due to displacements in the system should not exceed the allowable stress range, the reactions shall not be detrimental to supports or other connections, the movement of the piping shall be within any prescribed limits and properly accounted for in flexibility calculations $[1,2]$. When a pipe is fully restrained and not free to expand or shrink with changes of temperature tensile or compressive stress and excessive forces will result in damage or failure of the structures. The stress range due to expansion loads using the requirements of ASME B31.3 establishes the maximum allowable stress limits that can be safely accommodated by a piping system before failure. This Code defines the concept of stress range under cold and hot operating conditions using the equation $[1,2]$ :

$$
S_{A}=f\left(1.25 S_{C}+0.25 S_{h}\right) E_{h} / E_{C}
$$

where: $S_{A}$ is the allowable thermal expansion stress range of the piping system of the same material and temperature $[\mathrm{MPa}], S_{C}$ is the allowable stress for the cold condition $[\mathrm{MPa}], S_{h}$ the allowable stress for the hot condition [MPa], $E_{C}$ is the reference modulus of elasticity at room temperature [MPa], $E_{h}$ the modulus of elasticity at maximum temperature $[\mathrm{MPa}]$ and $f$ is the stress range reduction factor from ASME B31.3 code. The stress range reduction factor $f$ is function of the number $N$ of equivalent full amplitude cycles during the expected service lifetime of the piping system, obtained using the equation:

$$
f=6(N)^{-0.2} \leq 1
$$

ASME B31.3 gives an approximate and useful formula for estimation the adequacy of the pipe flexibility between anchor points when subject to thermal expansion or shrink $[1,2]$. It applies when the pipe is with uniform diameter and 
with very simple geometry layout (a bend or two) with terminal anchors. This approximate formula is questionable and of little practical use in an age where piping analysis software is readily available [3], for instance:

$$
D_{e} y /(L-U)^{2} \leq 208
$$

where: $D_{e}$ is the outside diameter of pipe [mm],y is the resultant total displacement absorbed by the piping system $[\mathrm{mm}], L$ the length of piping between anchors $[\mathrm{m}]$ and $U$ the straight line between anchors [m].

The stress field due to thermal expansion tends to decrease with time, due the self springing, as shown in numerical results. For successive hot and cold cycle the creep influence is considered and the displacement stress range remains constant during all cycles. The self springing is a slow process and can be different along pipe system due the stress variation.

\section{Numerical model}

The finite element program Cosmos/ $M$ was used to model and analyse the thermal and mechanical behaviour of steel piping system exposed to fire conditions. A geometrical and material non-linear model is employed to predict the development of transient thermal stresses. This non-linearity is treated by an iterative procedure in each time step based on the Newton-Raphson method. Thin finite shell element (SHELL4) is used for nonlinear analysis with 6 degrees of freedom per node. For mechanical analysis an elastoplastic and isotropic hardening (von-Mises) model was used. For transient thermal analysis, standard temperature-time curve ISO834 was used for environment temperature transition according EC1 [4], obtained with:

$$
T_{\infty}=20+345 \log _{10}(8 t+1)
$$

\subsection{Material proprieties}

Steel temperature dependent material properties are used for this analysis according to EC3 [5]. The unit mass may be considered independent temperature parameter and the value adopted is $7850 \mathrm{~kg} / \mathrm{m}^{3}$. The relationship between thermal elongation and steel temperature, assuming a simple calculation, may be considered equal to $14 \times 10^{-6} /{ }^{\circ} \mathrm{C}$.

The specific heat of steel may be determined from the following formulas:

$$
C=\left\{\begin{array}{cc}
425+7.73 \times 10^{-1} T-1.69 \times 10^{-3} T^{2}+2.22 \times 10^{-6} T^{3} & 20^{\circ} C \leq T<600^{\circ} C \\
666+\frac{13002}{738-T} & 600^{\circ} C \leq T<735^{\circ} C \\
545+\frac{17820}{T-731} & 735^{\circ} C \leq T<900^{\circ} C \\
650 & 900^{\circ} C \leq T \leq 1200^{\circ} C
\end{array}\right.
$$

The thermal conductivity of steel is obtained, according the following equations:

$$
\lambda=\left\{\begin{array}{cc}
54-3.33 \times 10^{-2} T & 20^{\circ} C \leq T<800^{\circ} C \\
27.3 & 800^{\circ} C \leq T \leq 1200^{\circ} C
\end{array}\right.
$$


Strength and deformation properties are determined according to the reduction factors $K$ in EC3 [4], for stress-strain relationship at elevated temperatures. The elasticity modulus $E$ and yielding stress $f_{Y}$ variation is obtained according these reduction factors, as represented in figure 1.

\section{Flexibility analysis}

Different geometry piping systems exposed to fire conditions with built ends constraints were analysed using the finite element method. Axisymmetric boundary thermal conditions across pipe sections were considered. Figure 2 represents the tested geometry, where reference is made to different types of hollow tubular sections to be studied, considering the external diameter $\mathrm{De}=508[\mathrm{~mm}], \mathrm{De}=406[\mathrm{~mm}]$ and $\mathrm{De}=273[\mathrm{~mm}]$, and for different thickness as represented in Table 1.

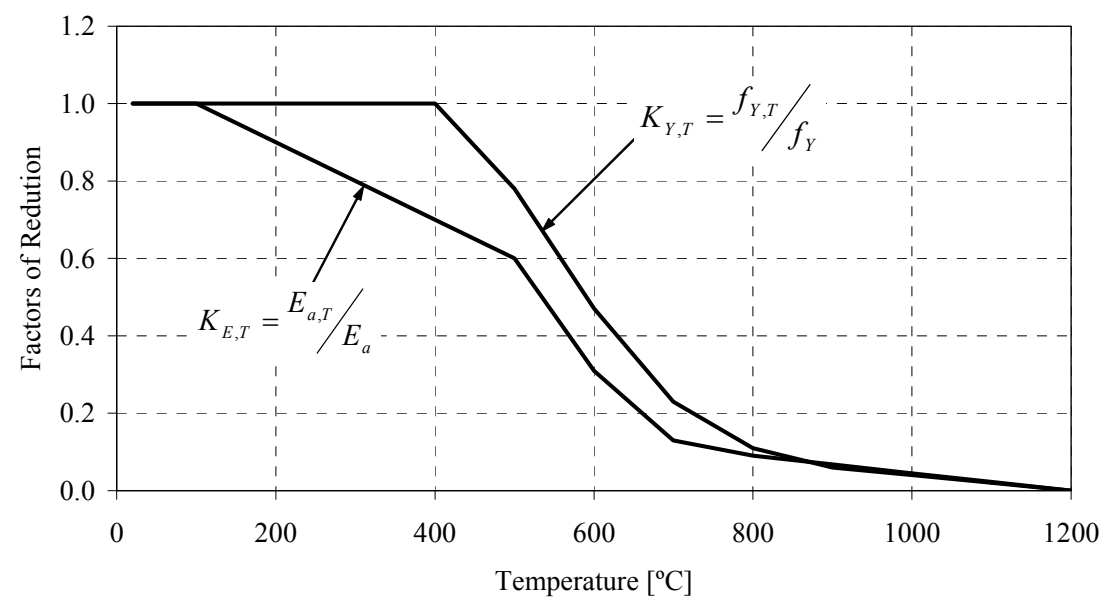

Figure 1: Modulus of elasticity variation.

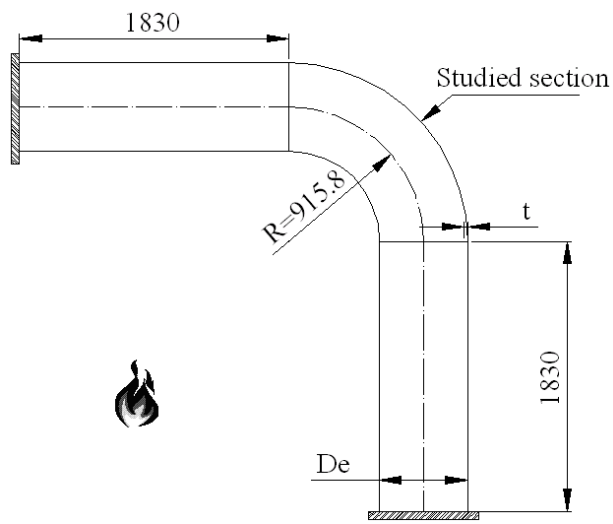

Figure 2: Geometry used for numerical analysis. 
Figures 3-5 show the temperature evolution for different hollow section thickness during one hour. For small values of the pipe thickness-medium radius ration the thermal behaviour may be considered uniform. When the pipe thickness decreases the temperature field increases, for all studied pipes. For thinner pipes the fire temperature resistance is lowest than for thick-walled pipes.

Figures 6-8 represent the equivalent stress, function of time, for different hollow tubular sections. The curves represent the maximum stress obtained and a state stress during a transient time, representing the self springing. The critical temperature was also obtained for different geometric sections and represented in Table 1.

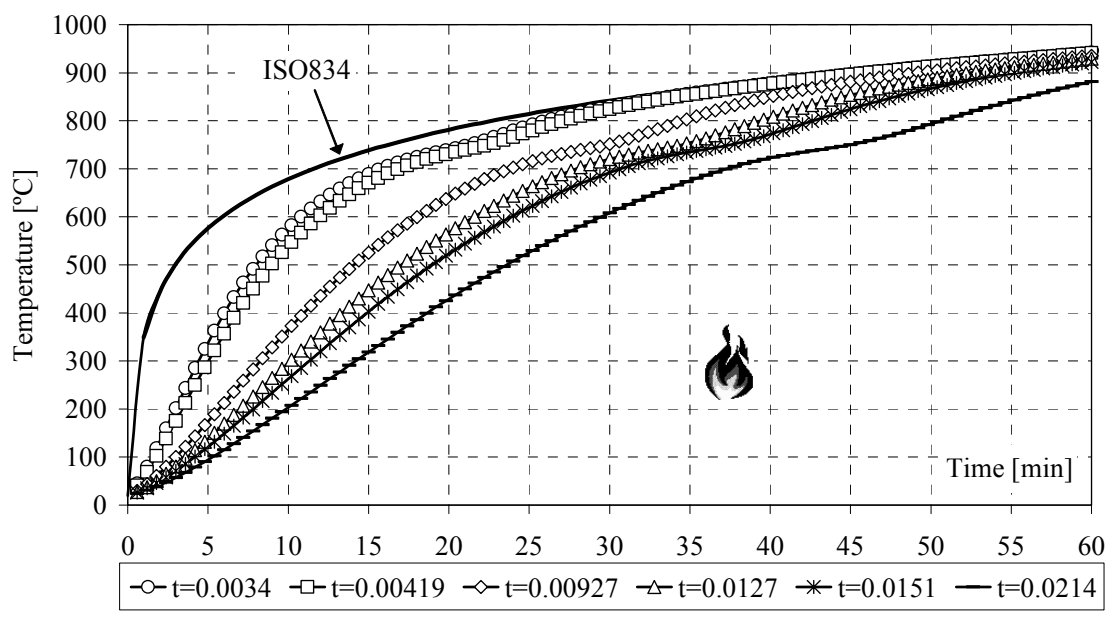

Figure 3: Time temperature history $[\mathrm{De}=273 \mathrm{~mm}]$.

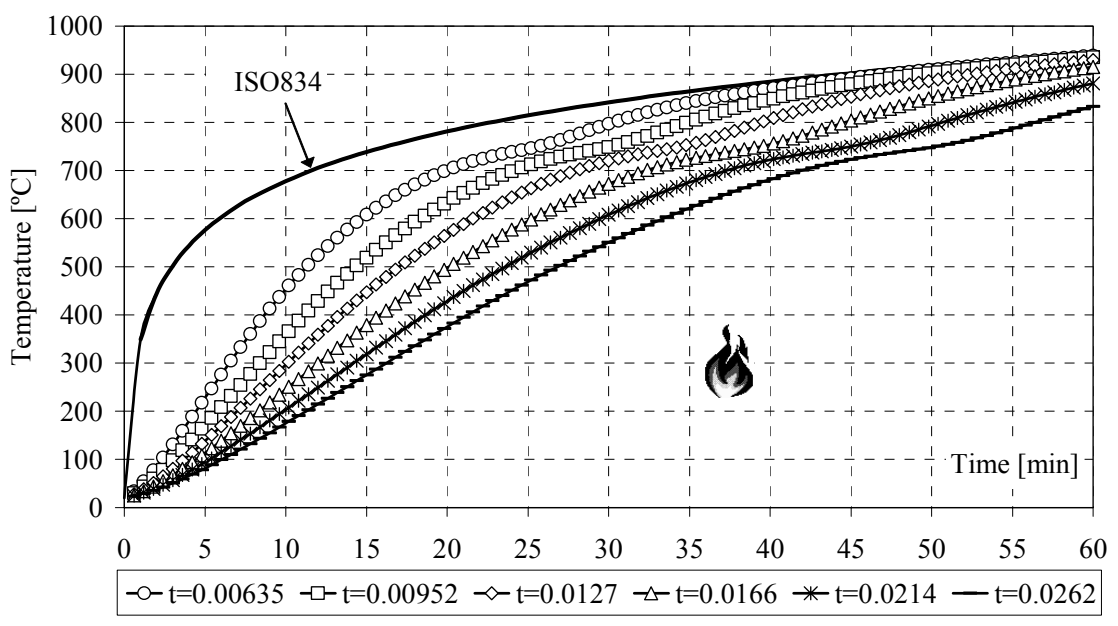

Figure 4: Time temperature history [De $=406 \mathrm{~mm}]$. 


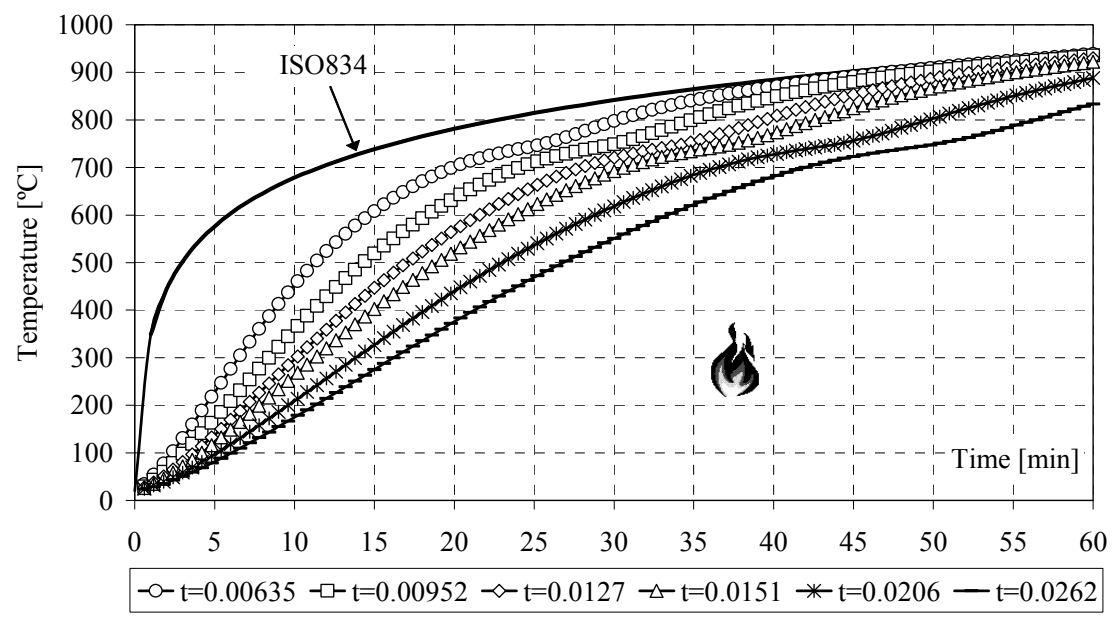

Figure 5: Time temperature history $[\mathrm{De}=508 \mathrm{~mm}]$.

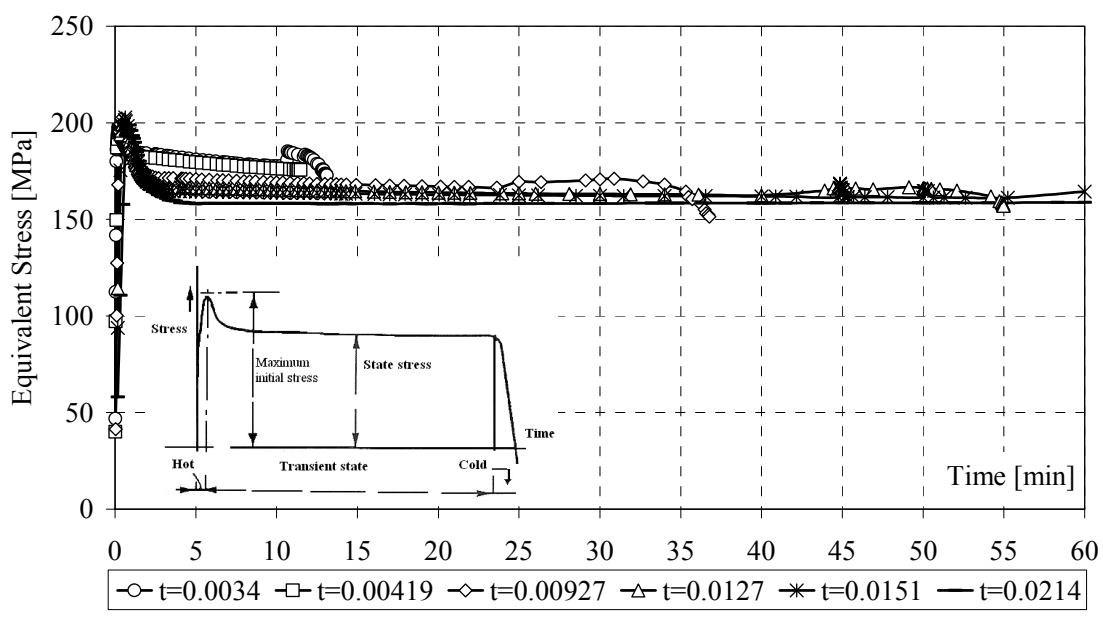

Figure 6: Equivalent stress variation $[\mathrm{De}=273 \mathrm{~mm}]$.

Figures 9-11 represent the total displacement absorbed by the piping system for different hollow section thickness during fire exposure. This value was obtained for the middle hollow section represented in figure 2.

Table 1 shows the maximum initial stress at room temperature, the total displacement obtained due to thermal expansion and the results obtained using Equation 3. Several time instants, after the beginning of the plastic behaviour and different equivalent stresses values, are represented for different tubular section stiffness. At critical maximum temperature the total displacement is obtained in nonlinear stage. These values increase with the greater value of temperature and for stiffeners pipes. 


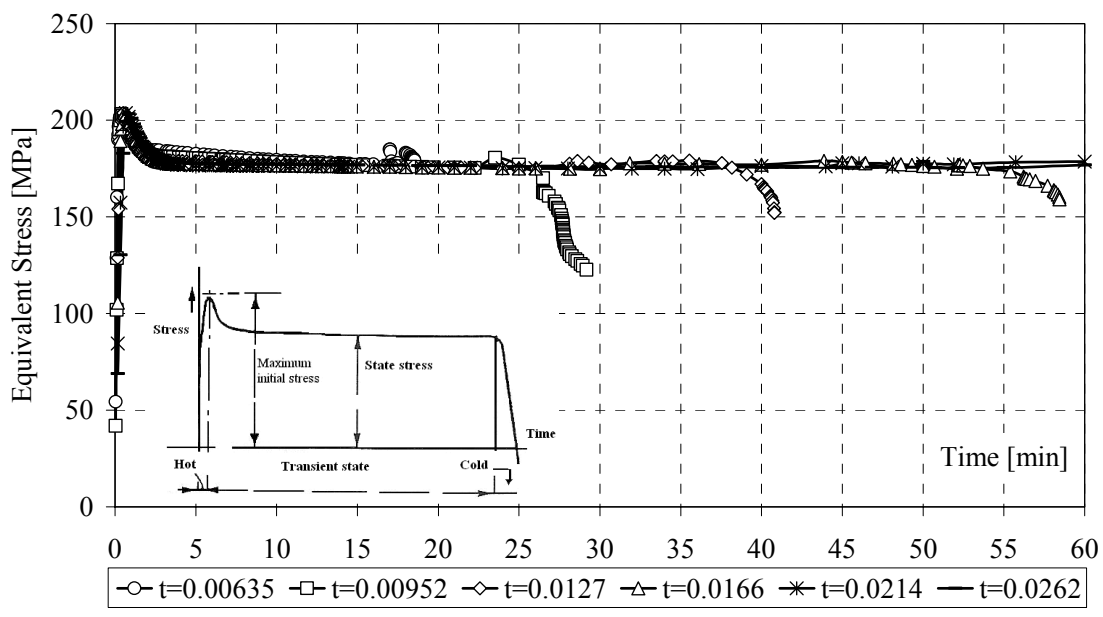

Figure 7: Equivalent stress variation $[\mathrm{De}=406 \mathrm{~mm}]$.

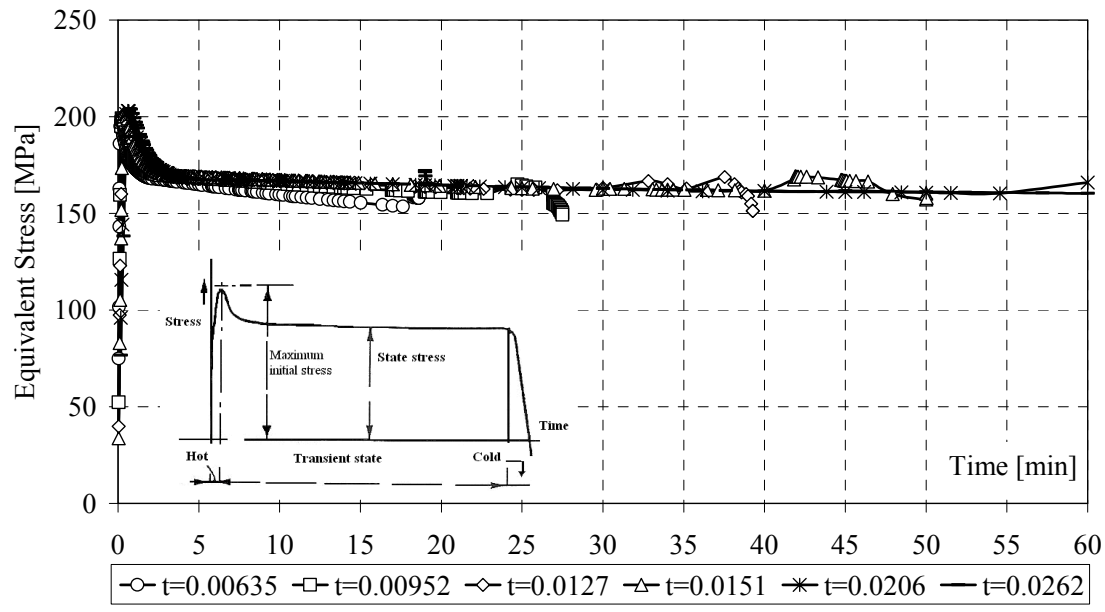

Figure 8: Equivalent stress variation $[\mathrm{De}=508 \mathrm{~mm}]$.

\section{Conclusions}

A computational program, based on the finite element method to model the thermo-elastoplastic behaviour of steel tubular hollow structures exposed to the standard fire curve ISO834, had been used. The numerical results were compared with those coming from the simplified code, as in Equation 3. For this situation the values of the temperature are always at room temperature and the equivalent stress is below the allowable stresses from simplified code Equation 1. Thermal stresses were calculated during fire exposure, using temperature dependent 
properties. The self-springing effect was identified for all numerical simulations. The critical temperature was determined for each piping hollow section. With this information, restrains, guides and anchors can be added or a new material can be selected. Different tubular section with an appropriate safety level or a thermal protection material can be used if necessary. Therefore, with this type of analysis it is possible to retain a deep understanding of the system flexibility, turning out to be useful in the design of tubular structures.

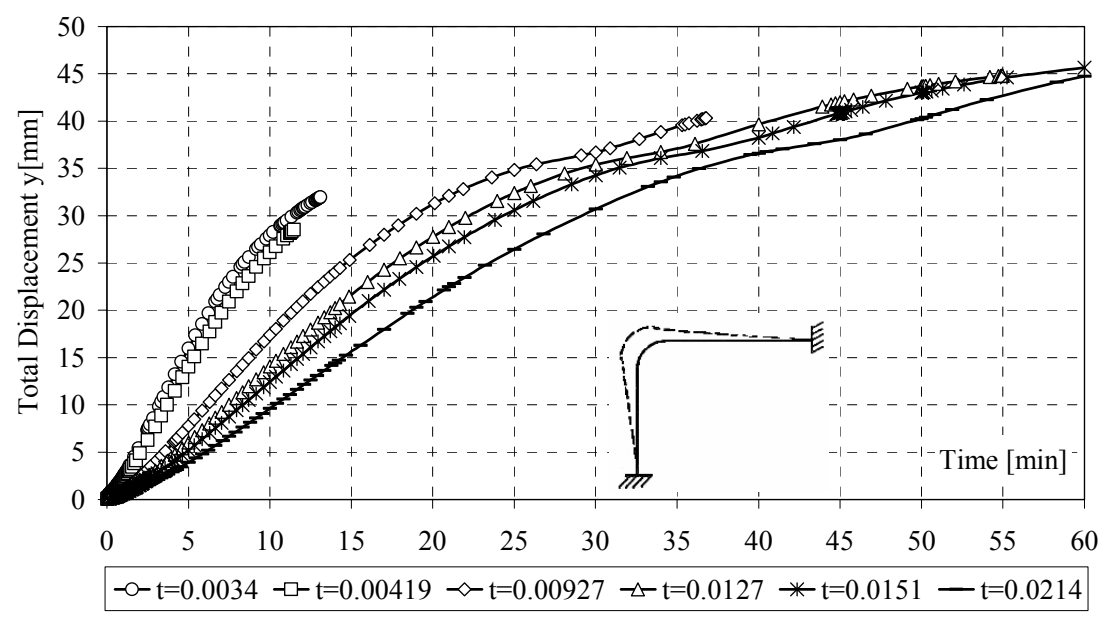

Figure 9: $\quad$ Total displacement $[\mathrm{De}=273 \mathrm{~mm}]$.

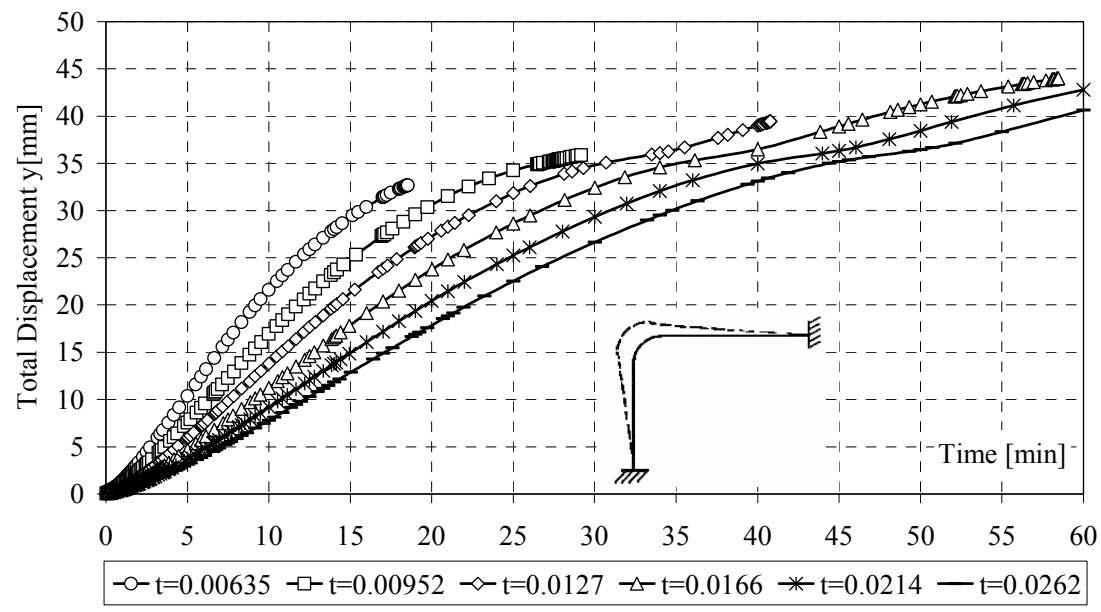

Figure 10: Total displacement $[\mathrm{De}=406 \mathrm{~mm}]$. 


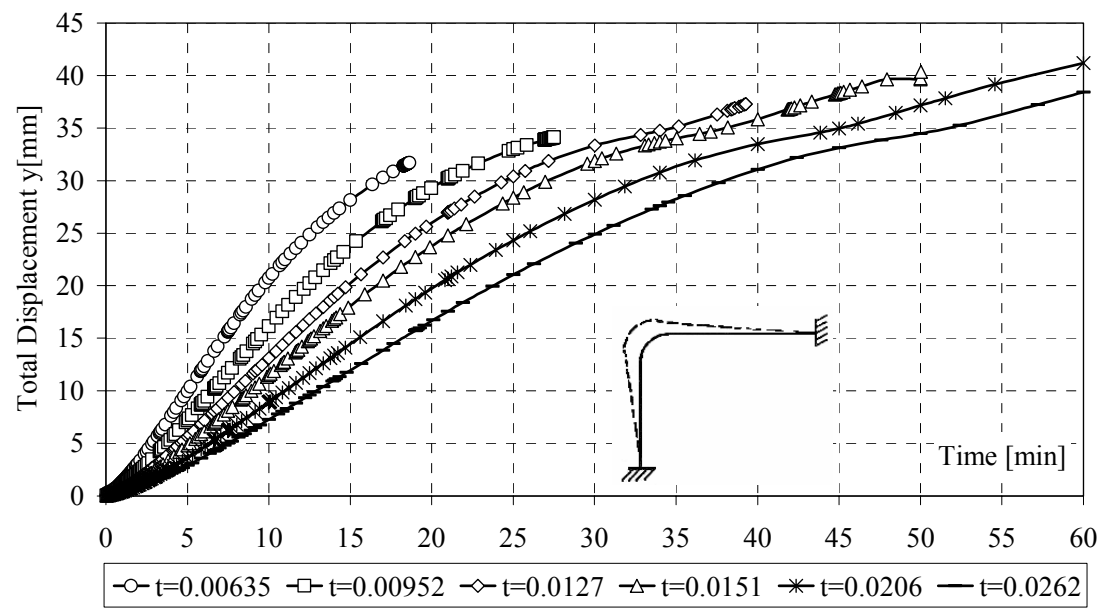

Figure 11: Total displacement $[\mathrm{De}=508 \mathrm{~mm}]$.

Table 1: $\quad$ Numerical results.

\begin{tabular}{|c|c|c|c|c|c|c|c|c|c|c|}
\hline \multirow{2}{*}[\mathrm{mm}]{} & \multirow{2}{*}{$\mathrm{t}[\mathrm{mm}]$} & \multirow{2}{*}{$t / r$} & \multicolumn{4}{|c|}{ Maximum initial stress (room temperature) } & \multicolumn{4}{|c|}{ Ultimate stress } \\
\hline & & & Eq 3 & time [min] & Stress[MPa] & $\mathrm{y}[\mathrm{mm}]$ & time [min] & Stress[MPa] & $\mathrm{y}[\mathrm{mm}]$ & Temp $\left[{ }^{\circ} \mathrm{C}\right]$ \\
\hline \multirow{6}{*}{$\begin{array}{l}\infty \\
\stackrel{\infty}{\infty} \\
\stackrel{0}{0} \\
\stackrel{0}{0}\end{array}$} & 6.35 & 0.03 & 41.24 & 0.20 & 195.00 & 0.21 & 18.63 & 158.00 & 31.69 & 537.00 \\
\hline & 9.52 & 0.04 & 41.24 & 0.29 & 199.00 & 0.21 & 27.50 & 149.00 & 34.12 & 696.00 \\
\hline & 12.70 & 0.05 & 45.16 & 0.41 & 200.00 & 0.23 & 39.28 & 151.00 & 37.29 & 796.00 \\
\hline & 15.10 & 0.06 & 49.09 & 0.54 & 200.00 & 0.25 & 50.03 & 158.00 & 40.36 & 870.00 \\
\hline & 20.60 & 0.08 & 49.09 & 0.67 & 203.00 & 0.25 & 60.00 & 166.00 & 41.18 & 888.00 \\
\hline & 26.20 & 0.11 & 47.13 & 0.77 & 204.00 & 0.24 & 60.00 & 160.00 & 38.41 & 833.00 \\
\hline \multirow{6}{*}{$\begin{array}{l}\text { \& } \\
\text { Jা } \\
\stackrel{0}{0}\end{array}$} & 6.35 & 0.03 & 73.76 & 0.41 & 202.00 & 0.47 & 18.54 & 179.00 & 32.69 & 681.00 \\
\hline & 9.52 & 0.05 & 48.65 & 0.40 & 202.00 & 0.31 & 29.17 & 123.00 & 35.87 & 791.00 \\
\hline & 12.70 & 0.06 & 36.09 & 0.50 & 204.00 & 0.23 & 40.79 & 152.00 & 39.44 & 874.00 \\
\hline & 16.60 & 0.09 & 40.80 & 0.56 & 204.00 & 0.26 & 58.45 & 159.00 & 44.01 & 935.00 \\
\hline & 21.40 & 0.11 & 53.36 & 0.83 & 202.00 & 0.34 & 60.00 & 179.00 & 42.77 & 939.00 \\
\hline & 26.20 & 0.14 & 43.94 & 0.83 & 203.00 & 0.28 & 60.00 & 177.00 & 40.63 & 939.00 \\
\hline \multirow{6}{*}{$\begin{array}{l}\stackrel{0}{\Delta} \\
\underset{0}{0}\end{array}$} & 3.40 & 0.03 & 61.20 & 0.28 & 194.00 & 0.58 & 13.10 & 173.00 & 31.94 & 658.00 \\
\hline & 4.19 & 0.03 & 40.10 & 0.22 & 196.00 & 0.38 & 11.48 & 176.00 & 28.53 & 586.00 \\
\hline & 9.27 & 0.07 & 41.15 & 0.32 & 202.00 & 0.39 & 36.37 & 151.00 & 40.32 & 822.00 \\
\hline & 12.70 & 0.10 & 45.37 & 0.67 & 200.00 & 0.43 & 54.98 & 157.00 & 44.79 & 910.00 \\
\hline & 15.10 & 0.12 & 35.88 & 0.64 & 203.00 & 0.34 & 60.00 & 164.00 & 45.68 & 922.00 \\
\hline & 21.40 & 0.17 & 41.15 & 0.90 & 199.00 & 0.39 & 60.00 & 159.00 & 44.75 & 881.00 \\
\hline
\end{tabular}

\section{References}

[1] ASME Code for Pressure Piping, B31, ASME B31.3, Process Piping, 2002.

[2] BS EN 13480-3:2002, Metallic Industrial Piping - Part 3: Design and Calculation, 2002. 
180 Safety and Security Engineering II

[3] George A. Antaki, Piping and Pipeline Engineering: Design, Construction, Maintenance, Integrity and Repair, Marcel Dekker Inc: USA, 2003.

[4] CEN ENV 1991-2-2, Eurocode 1: Basis of Design and Actions on Structures - Part 2-2: Actions on Structures - Actions on Structures Exposed to Fire, 1995.

[5] CEN ENV 1993-1-2, Eurocode 3: Design of Steel Structures - Part 1.2: General Rules - Structural Fire Design, 1995. 